\title{
CONHECIMENTOS QUE AGENTES COMUNITÁRIOS DE SAÚDE E CUIDADORES DE IDOSOS TÊM SOBRE SAÚDE BUCAL NA VELHICE: experiências da estratégia de saúde da família de Victor Graeff - RS
}

\author{
Eloísa Kuhn Wentz ${ }^{1}$ \\ Marilene Rodrigues Portella ${ }^{2}$
}

\section{Resumo}

O presente estudo teve como objetivo identificar qual o conhecimento que os CI (Cuidadores de Idosos) e os ACS (Agentes Comunitários de Saúde) da área de abrangência da ESF (Estratégia de Saúde da Família) do município de Victor Graeff-RS têm acerca dos cuidados e saúde da bucal dos idosos. Participaram oito ACS e quatro CI. A coleta de dados ocorreu por meio de entrevistas semidirigidas, de caráter grupal. Os dados foram analisados qualitativamente valendo-se da construção de categorias analíticas. Os resultados permitiram identificar alguns aspectos sobre o conhecimento e as dificuldades que os ACS e CI têm a respeito da saúde e cuidados bucais dos idosos, e também as orientações que os ACS repassam aos CI durante as visitas domiciliares.

Palavras-chave: Gerontologia. Saúde bucal. Agente comunitário de saúde. Idoso. Cuidadores de idosos. Estratégia de Saúde da Família.

\section{Introdução}

Parajara e Guzzo (2000) relatam que, conforme dados de entidades internacionais, daqui a trinta anos dois terços da atividade odontológica estarão direcionados para o atendimento da população acima de 65 anos, sendo que a tendência atual é que o indivíduo envelheça com os dentes, visto a grande preocupação tanto da população da terceira idade quanto dos profissionais de saúde com a promoção e a manutenção da saúde bucal em todas as fases do ciclo da vida.

\footnotetext{
1 Cirurgiã-Dentista. Especialista em Saúde da Família pela Universidade de Passo Fundo (UPF). E-mail: eloisakw@yahoo.com.br

2 Professora Titular do Curso de Enfermagem do Instituto de Ciências Biológicas da Universidade de Passo Fundo (ICB/UPF). Doutora em Enfermagem pela Universidade Federal de Santa Catarina (UFSC). Líder do Grupo de Pesquisa Vivencer UPF/CNPq. E-mail: portella@upf.br
} 
Segundo Mastrantonio e Garcia (2002), a cárie dental e a doença periodontal são os dois maiores problemas de saúde pública em Odontologia, devido aos seus elevados índices, atingindo grande parte da população brasileira. Frente a isso, a Odontologia atual deve estar voltada fundamentalmente para a prevenção e educação em saúde bucal. No mesmo estudo, Costa e Albuquerque (1997) ${ }^{3}$ referem que atitudes e comportamentos podem ser modificados a partir da educação em saúde, o que favorece a formação de hábitos saudáveis, os quais trazem muitos benefícios para a saúde.

$\mathrm{Na}$ fala de Parajara e Guzzo (2000), o centro da sede nos idosos tem sua função diminuída, razão pela qual estas pessoas ingerem menos água, o que aumenta o risco de desidratação de tecidos moles e mucosas, como as da boca, propiciando, em muitos casos, o aparecimento de algumas patologias. Além da desidratação dos tecidos orais pelo pouco consumo de líquidos, o uso de alguns medicamentos também reflete no ambiente oral, principalmente tornando a boca seca, fenômeno que, muitas vezes, não é valorizado pelos idosos ou cuidadores.

Segundo a pesquisa de Kina, Beloti e Brunetti (1998), as alterações salivares na senescência, que compreende a diminuição do fluxo salivar por um declínio das células acinares produtoras de saliva, não traz efeitos em pessoas idosas sadias. Porém, alguns fatores, isolados ou em conjunto, podem prejudicar as condições de saúde oral acarretando xerostomia, processos cariosos desenfreados, candidíase e alterações na mucosa bucal. O uso de certas drogas, como alguns antidepressivos e anti-hipertensivos, algumas enfermidades e tratamentos com quimioterápicos são exemplos de fatores causadores dos problemas anteriormente citados.

Para Ferreira, Magalhães e Moreira (2004), é importante considerar, inicialmente, a condição funcional do idoso para que a condução do cuidado seja adequada. Um idoso parcialmente dependente necessitará de algum suporte, sendo que a orientação deverá ser feita ao idoso e ao cuidador. Para o idoso dependente, a responsabilidade é exclusiva do cuidador, e consultas habitualmente serão realizadas no domicílio. Já para idosos independentes uma outra conduta poderá ser aplicada. Orientações de cuidados e higiene oral voltadas especificamente ao público senil, bem como atendimentos curativos e preventivos levando-se em consideração as peculiaridades dos idosos, são exemplos de trabalhos a serem realizados com idosos independentes.

3 COSTA, Ires do Céu Clara; ALBUQUERQUE, Ademir Jose. Educação para a Saúde: odontologia preventiva e social. Natal: Ed. da UFRN, 2007. Apud MASTRANTONIO; GARCIA, 2002. 
Na opinião de Costa Neto (2000), o Programa de Saúde da Família (PSF), o qual atualmente é denominado Estratégia de Saúde da Família (ESF), vem sendo entendido como uma inovadora estratégia para as ações no setor da saúde e configura-se como uma nova concepção de trabalho, trazendo o esforço em equipe como forma de diversificar as atitudes e ações com base na interdisciplinaridade, tratando a família e a comunidade como foco principal das diversas ações compreendidas entre trabalhos clínicos e promoção da saúde. Dentro desta visão, os Agentes Comunitários de Saúde (ACS), como parte dos profissionais da ESF, funcionam como elos entre a equipe e comunidade, à medida que estão em permanente contato com as famílias, identificando situações de risco, acompanhando e orientando as mesmas, desenvolvendo ações de vigilância em saúde com ênfase na promoção de saúde e prevenção de doenças.

Pavarini et al. (2001) reconhecem que, com o aumento da expectativa de vida e com o crescente número de pessoas idosas na população, a dinâmica familiar está mudando, ou seja, os papéis dentro da família ganham novos contornos, ao passo que se torna imprescindível a ação do cuidador. Cuidar de uma pessoa idosa, principalmente se esta pertencer à família, requer respeito, afetividade, entendimento sobre o envelhecimento e reorganização das tarefas diárias, ações as quais envolvem idoso e cuidador. Tal fato acarreta inúmeras alterações na dinâmica familiar.

Cerqueira e Oliveira (2002) discorrem sobre o fato de que existe uma necessidade de oferecer suporte para os cuidadores de idosos, principalmente de familiares, através de programas de apoio, dentro das políticas do serviço público. Estes programas devem destinar-se a prevenir a sobrecarga e o impacto emocional negativo que podem afetar a saúde e a qualidade de vida de cuidadores de idosos e de outras pessoas dependentes.

Observa-se, de certa forma, um grande desconhecimento dos ACS e dos cuidadores de idosos (CI) acerca da importância da saúde bucal do idoso. Tal fato pode contribuir para o prejuízo de sua saúde física e mental. Desta forma, uma higiene oral insuficiente ou ausente, bem como uma nãoobservação dos fatores bucais anormais, pode lesar o estado nutricional, a fala, a comunicação e a auto-estima. Assim, do ponto de vista da influência que a saúde bucal pode ter na manutenção de uma boa qualidade de vida, exatamente a população idosa representa uma nítida prioridade para a ESF e os CI.

É importante salientar que o estudo se reveste de significativa relevância para o campo da Saúde da Família na medida em que representa 
uma possibilidade de contribuir com o trabalho direcionado ao idoso, na formulação e execução de ações de saúde.

O papel de educar para a saúde bucal não deve ser atribuído somente ao cirurgião-dentista, apesar de ser este o profissional responsável pela difusão dos conhecimentos à população. Esta tarefa pode ser efetuada de forma direta, ou seja, através do contato do próprio cirurgião-dentista com os grupos e/ou pessoas afins, ou indiretamente, por meio da capacitação e treinamento de pessoas ou grupos.

Desta forma, é importante a identificação, a conscientização e a capacitação dos agentes que possam compartilhar com o profissional da área odontológica o importante papel de educar para a saúde, ou seja, as pessoas que interagem direta ou indiretamente com a parcela senil da sociedade: familiares, cuidadores, ACS e demais integrantes da ESF.

Nesse sentido, esta pesquisa teve como objetivo verificar o conhecimento que os ACS e os CI têm acerca dos cuidados necessários à saúde bucal dos idosos atendidos pela ESF do município de Victor Graeff - RS. Procurou-se identificar as orientações dos ACS e CI sobre o assunto, reconhecer as práticas de cuidados conhecidas e utilizadas por eles na prevenção e promoção da saúde bucal do idoso, averiguar dificuldades e facilidades encontradas pelos mesmos com relação aos aspectos bucais dos atendidos, bem como promover uma discussão com esses profissionais sobre a importância das medidas de cuidados na prática desse trabalho junto à população-alvo.

\section{Materiais e Métodos}

Tratou-se de um estudo de caráter exploratório, descritivo, com abordagem qualitativa. Os dados foram coletados por meio de entrevistas semidirigidas, de caráter grupal, com auxílio de um roteiro norteador, tanto para os ACS quanto para os CI. Para o desenvolvimento deste trabalho, obteve-se a autorização da Secretaria Municipal de Saúde. O projeto foi apresentado ao Comitê de Ética em Pesquisa da Universidade de Passo Fundo e obteve aprovação para sua execução com o parecer consubstanciado de projeto de pesquisa - registro no Comitê de Ética em Pesquisa (CEP) 131/2006. A coleta dos dados foi realizada em encontros com os dois grupos focos da pesquisa: ACS no mês de setembro e CI em outubro de 2006. Foram incluídos neste estudo os oito ACS que atuam na equipe da ESF do município e quatro CI pertencentes às microáreas de atuação dos ACS. Através da assinatura de um termo de consentimento livre e esclarecido, os sujeitos autorizaram sua participação voluntária na pesquisa, assegurando o direito 
dos mesmos de retirar o consentimento em qualquer fase, sem nenhuma penalização ou prejuízo ao seu cuidado. Os sujeitos tiveram assegurada sua privacidade quanto aos dados confidenciais da pesquisa. Foram expostos os objetivos do trabalho, bem como os procedimentos aos quais seriam submetidos, assegurando o caráter confidencial de suas respostas e seu direito de não-identificação.

A coleta dos dados dos ACS foi realizada em encontro que os mesmos realizam rotineiramente, na sala de reuniões da Unidade Básica de Saúde, com $100 \%$ de participação. Com os CI os dados foram colhidos durante encontro na sala de reuniões da Associação dos Pais e Amigos dos Excepcionais (APAE) do município. Os CI receberam convites formulados pela pesquisadora, entregues pelos ACS durante visitas domiciliares de rotina.

Receberam convite 31 Cuidadores de Idosos, sendo que 4 destes compuseram o grupo da coleta dos dados. A amostra que compareceu ao encontro representou $13 \%$ do total de CI do município.

Os conhecimentos dos ACS e CI acerca da saúde bucal dos idosos foram verificados através das respostas às questões como: problemas bucais dos idosos comumente detectados pelos ACS e CI; dificuldades percebidas pelos CI no que se refere à higienização bucal dos idosos; informações sobre cuidados e saúde bucal do idoso difundidas pelo ACS nas visitas domiciliares.

Através do roteiro norteador contendo estas questões, coletaram-se os dados qualitativos da pesquisa. Para registro das respostas, contou-se com o auxílio de um anotador (pessoa convidada para executar esta função), recurso de um gravador e fita cassete. Durante as entrevistas, manteve-se um caráter informal, a fim de que os participantes se sentissem à vontade para relatar suas impressões a respeito dos cuidados de higiene oral e saúde bucal dos idosos.

Os procedimentos de análise e interpretação dos dados tiveram como orientação a construção de categorias, sendo que as informações colhidas nas entrevistas foram agrupadas em temas, expostos em forma de quadros e, em seguida, as falas foram analisadas com o intuito de verificar o conhecimento que os ACS e CI têm acerca dos cuidados necessários à saúde bucal dos idosos. Segundo Minayo (1995), categorias são empregadas para estabelecer classificações, ou seja, agrupar elementos, idéias ou expressões, em torno de um conceito capaz de abranger qualquer tipo de análise em pesquisa qualitativa. 


\section{Apresentação dos Resultados}

A análise das respostas possibilitou a classificação em forma de categorias, sendo elas: 1 - Conhecimento sobre saúde bucal; 2 - Dificuldades e problemas percebidos; 3 - O fazer educativo dos ACS. Para uma melhor compreensão do leitor, iniciamos com a apresentação do cenário e uma descrição sucinta dos participantes do estudo.

\subsection{O Cenário e os Participantes do Estudo}

Foram envolvidos na pesquisa oito ACS - um do sexo masculino e sete do sexo feminino - com idades entre 21 e 55 anos. Destes ACS, dois atuam na zona urbana e seis em áreas rurais. $\mathrm{O}$ tempo médio de atuação destes participantes foi de um ano e três meses nas microáreas urbanas, e de dois anos e dois meses nas rurais. Quanto ao grau de instrução dos ACS, o grupo apresentou formação nos cursos de graduação em Educação Física, Auxiliar de Enfermagem, Ensino Fundamental e Ensino Médio.

Após cálculo entre os meses de janeiro a outubro de 2006, obteve-se um número de famílias cadastradas e de famílias acompanhadas em cada microárea (Tabela 1).

Tabela 1 - Situação dos ACS quanto à microárea de atuação, localização e média das famílias cadastradas e acompanhadas.

\begin{tabular}{cccc}
\hline Microárea & Localização & $\begin{array}{c}\mathbf{N}^{\circ} \text { médio de famílias } \\
\text { cadastradas }\end{array}$ & $\begin{array}{c}\mathbf{N}^{\circ} \text { médio de famílias acompa- } \\
\text { nhadas - visitas domiciliares }\end{array}$ \\
\hline 01 & Zona rural & 75 & 54 \\
02 & Zona rural & 92 & 71 \\
03 & Zona rural & 94 & 72 \\
04 & Zona rural & 94 & 75 \\
05 & Zona rural & 83 & 78 \\
06 & Zona rural & 115 & 94 \\
07 & Zona urbana & 255 & 125 \\
08 & Zona urbana & 233 & 102 \\
\hline
\end{tabular}

Para a realização do cálculo, utilizaram-se os dados contidos no Sistema de Informação de Atenção Básica (SIAB) da Secretaria Municipal de Saúde. Conforme informações do sistema, a porcentagem de pessoas idosas cadastradas - ou seja, a população acima de 60 anos - corresponde a 
aproximadamente $16 \%$ da população total; isto é, de 3.150 habitantes, 530 são idosos, sendo 241 homens e 289 mulheres (BRASIL, 2006).

Cabe salientar que os dados do SIAB são variáveis podendo sofrer modificações a cada mês devido a vários fatores como imigração e emigração de pessoas nesta faixa etária, óbitos e aumento de habitantes com 60 anos ou mais.

Problemas como hipertensão arterial, diabetes e patologias reumatológicas representam os agravos de saúde mais comumente encontrados nesta faixa etária, conforme informações das ACS, sendo que o sistema de informações utilizado não fornece este tipo de dado.

O grupo de CI foi composto por quatro pessoas, todas do sexo feminino, com idades entre 35 e 57 anos, sendo duas da zona urbana e duas da zona rural. Quanto ao grau de parentesco, duas cuidadoras eram filhas e duas eram noras dos idosos cuidados. Uma das cuidadoras estava concluindo curso de nível superior (Graduação em Letras) e as outras três tinham escolaridade de nível fundamental. O tempo médio de experiência nesta atividade foi de 14,5 anos, sendo a CI com menor tempo de experiência tinha cinco anos, e a experiência mais longa era de 20 anos.

Dos idosos cuidados, um era homem (81 anos) e três eram mulheres (61, 81 e 84 anos), sendo que uma idosa encontrava-se acamada necessitando de cuidados permanentes. Problemas visuais, comprometimento de vesícula e pulmão, seqüelas de derrame e infarto foram os principais problemas de saúde dos idosos, relatados pelas CI.

Tomando como base que os cuidadores que compareceram ao grupo para a coleta dos dados pertenciam ao grupo familiar do idoso, Myssior (2004) comenta que as pessoas de mais idade têm o núcleo familiar como ponto de referência. Grande parte dos idosos está vinculada a uma rede de apoio familiar, cujos componentes ocupam papéis primordiais, essencialmente filhos e/ou filhas e cônjuges. É desta família que provém a tarefa de prestar cuidados ao idoso, possuindo uma posição privilegiada nas questões de segurança emocional e material da pessoa de mais idade.

\subsection{Categoria 1: conhecimento sobre saúde bucal}

Tomando como referência o depoimento de que "a saúde começa pela boca", Hebling (2003) discorre que os efeitos psicológicos da ausência total dos dentes são complexos e diversos, podendo afetar a vida social, relacionamento afetivo e comunicação. Da mesma forma, a perda parcial dos dentes pode gerar diminuição da função mastigatória, dificultando a 
ingestão de alimentos, ricos em nutrientes, que, por sua vez, pode induzir alterações e/ou doenças sistêmicas no idoso.

No Quadro 1 pode-se observar o conhecimento que os ACS e CI participantes do estudo têm sobre cuidados e saúde bucal dos idosos.

Quadro 1 - Conhecimento dos Agentes Comunitários de Saúde (ACS) e Cuidadores de Idosos (CI) sobre a saúde bucal dos idosos.

\begin{tabular}{|l|l|}
\hline \multicolumn{1}{|c|}{ Agentes Comunitários de Saúde } & \multicolumn{1}{c|}{ Cuidadores de Idosos } \\
\hline - A saúde começa pela boca; & - Limpeza das próteses; \\
- Ter uma boa higiene; & - Escovação dos dentes. \\
- Idosos precisam de ajuda e auxílio no cuidado com os dentes; & \\
- Cuidados com "chapas", pontes e feridas; & \\
- Higiene bucal pelo menos três vezes ao dia, escovar os dentes & \\
e a língua após cada refeição; & \\
- Inspeção freqüente na boca, observando feridas, manchas, & \\
dentes manchados, com cárie e dores na boca em geral; & \\
- A pessoa idosa tem que continuar a cuidar dos dentes e fre- & \\
qüentar o dentista. & \\
\hline
\end{tabular}

Jitomirski (2000) comenta que a qualidade da saúde bucal no envelhecimento depende essencialmente dos aspectos preventivos e de manutenção, podendo ser definida como ausência de dor bem como um estado funcional saudável físico, social e psicológico. Tais aspectos refletem na qualidade de vida geral do indivíduo ou, quando não observados e tratados nos diversos aspectos ligados à saúde oral, podem transformar-se num problema adicional.

A inspeção freqüente da cavidade bucal, observando feridas, manchas nos dentes, cáries e dores na boca em geral, constitui-se em outro ponto importante relatado pelos ACS no tocante ao conhecimento sobre a saúde bucal dos idosos.

Pucca Júnior (1996) faz referência à mucosa bucal do idoso, que na ausência de doenças sistêmicas, costuma apresentar-se aparentemente normal. Contudo, em decorrência do envelhecimento torna-se mais susceptível à ruptura. A mucosa vai perdendo sua elasticidade tornando-se mais vulnerável, tendo como resposta o surgimento de ulcerações provocadas por traumatismos protéticos e outros devido à diminuição da irrigação sanguínea.

Os sujeitos da pesquisa, tanto os CI quanto os ACS, estão bem conscientes de que os idosos necessitam de ajuda e auxílio no cuidado com os aspectos bucais, incluindo a limpeza das próteses, a escovação dos dentes e 
a observação de alterações bucais, como feridas e manchas, principalmente aqueles que apresentam algum nível de dificuldade física ou motora.

As dificuldades de higiene oral, bem como a observação das alterações e afecções bucais apresentam-se como aspectos prejudicados nos idosos, haja em vista a diminuição da acuidade visual e problemas reumatológicos dos idosos em geral. Devido a estes fatores, Parajara e Guzzo (2000) discorrem que a higiene bucal, muitas vezes, fica comprometida quando a pessoa não enxerga bem o suficiente para conseguir fazer a sua higiene oral e perceber qualquer alteração na boca. Se o problema for de coordenação motora, a escovação, tarefa rotineira tão simples, torna-se muito difícil.

3.3 Categoria 2: dificuldades e problemas percebidos

A questão da higienização das próteses e o grande número de idosos portadores de aparelhos protéticos constituem-se num fato fortemente relatado pelos sujeitos da pesquisa, ao se tratar dos problemas bucais freqüentemente percebidos nos idosos (Quadro 2).

Quadro 2 - Problemas bucais comumente detectados pelos Agentes Comunitários de Saúde (ACS) e Cuidadores de Idosos (CI).

\begin{tabular}{|l|l|}
\hline \multicolumn{1}{|c|}{ Agentes Comunitários de Saúde } & \multicolumn{1}{c|}{ Cuidadores de Idosos } \\
\hline - Falta de higiene das próteses; & - Próteses mal ajustadas e \\
- Problemas gengivais; & lesões na boca associadas ao \\
- Uso expressivo de próteses; & emagrecimento do idoso; \\
- Perda de dentes naturais, muito freqüente em diabéticos; & - Dentes frouxos, evoluindo \\
- Dores nos dentes; & para a perda. \\
- Mau hálito; & \\
- Problemas sócio-econômicos para aquisição de próteses. & \\
\hline
\end{tabular}

Pucca Júnior (1996) discorre sobre o fato de a maioria dos idosos brasileiros apresentar grandes perdas de elementos dentários, sendo que uma parcela considerável deles é portadora de aparelhos protéticos.

Para a substituição dos dentes perdidos, o uso de aparelhos protéticos, principalmente as dentaduras totais, torna-se a solução.

Segundo Madeira e Madeira (2000), a grande maioria dos idosos ainda tem visão e crenças errôneas em relação à própria situação bucal, pensando que não precisam mais de cuidados odontológicos. Aceitam pacientemente os problemas bucais que vão surgindo com a idade, sentindo-se conformados com os mesmos e acreditando serem fatores irreversíveis em 
decorrência do processo de envelhecimento. Afirmam ainda que as próteses mal adaptadas e com dentes artificiais desgastados vão sendo aceitas pelos portadores mesmo que tais fatos prejudiquem ou inviabilizem as funções da fala, mastigação e estética.

Outra alteração freqüente na cavidade oral senil são os problemas periodontais que afetam muitos idosos, problemas estes relatados pelos ACS como freqüentemente encontrados nos idosos. Cabe salientar que, em decorrência destes, podem ocorrer perdas dentárias ou "afrouxamento dos dentes", conforme relatado pelos sujeitos da pesquisa.

Fajardo e Grecco (2003) relatam, em seu estudo, que pacientes diabéticos têm alta prevalência de problemas odontológicos, entre eles a candidíase, secura bucal, cáries e problemas periodontais.

Tão importante quanto substituir os dentes perdidos através da confecção criteriosa de aparelhos protéticos é a limpeza das próteses, higienização dos dentes remanescentes e dos tecidos da cavidade bucal. Carvalho e Cormack (2003) salientam que pacientes portadores de próteses, principalmente dentaduras, apresentam, na falta ou deficiência de higienização, infecções por microorganismos, como Candida albicans, processo fúngico que pode causar inflamação gengival ou halitose. Em sua pesquisa com 77 idosos, relataram que o método de eleição para a limpeza das próteses foi a escovação com dentifrício, seguido da imersão dos aparelhos protéticos em solução de hipoclorito de sódio.

Os ACS relataram que outro problema muito comum e que se torna um grande inconveniente durante as visitas domiciliares é a questão do mau hálito.

De acordo com Rodrigues, Vargas e Moreira (2003), o idoso sofre muito mais de halitose do que o adulto, pois a redução do fluxo salivar e a ocorrência de saburra lingual aumenta cerca de três vezes em relação ao adulto. $\mathrm{O}$ aumento da saburra pode estar relacionado ao aumento da ingestão de alimentos pastosos, liquefeitos e industrializados, muito presente na alimentação das pessoas senis. Assim, com a pouca ingestão de fibras, não ocorre a auto-higiene lingual. Outro fator que promove a diminuição do fluxo salivar - e, como conseqüência, a halitose - é o uso freqüente de medicamentos.

De acordo com Kina, Beloti e Brunetti (1998), na terceira idade o fluxo salivar é diminuído sendo bem suportado por pessoas idosas sadias. Contudo, uma série de fatores associados pode diminuir de modo significativo a taxa do fluxo salivar, provocando um processo de xerostomia. 
O uso de certos medicamentos, tratamentos como radioterapia e quimioterapia e algumas doenças auto-imunes afetam as glândulas salivares incapacitando-as de funcionar satisfatoriamente de modo a causar uma série de problemas como cáries rampantes, candidíase e friabilidade da mucosa.

A maioria dos idosos apresentava certa independência no cuidado, segundo relatos de seus cuidadores. Este fator pode ser de grande importância em se tratando da higiene oral do idoso, ao passo que o mesmo realiza sua higiene, não permitindo que o cuidador a faça ou auxilie.

Porém, quando o idoso insiste em realizar sua higiene oral sem ajuda do cuidador ou outra pessoa, alguns problemas podem vir a acontecer devido às dificuldades motoras, físicas ou psicológicas as quais acometem o público senil. A halitose, a insuficiente higiene das próteses, dentes e outras estruturas orais e os problemas gengivais são uns dos problemas decorrentes de práticas de higiene bucal deficientes muito comuns no período da velhice.

Muitas vezes, o idoso sente que está criando dificuldades para as tarefas rotineiras do cuidador, com a sensação de tornar-se um empecilho, por isso insiste em fazer sua própria higiene bucal. As dificuldades encontradas pelos cuidadores a respeito da higiene bucal dos idosos estão relatadas no Quadro 3.

Quadro 3 - Dificuldades percebidas pelos Cuidadores de Idosos (CI) no que se refere à higienização bucal dos idosos.

Insistência do idoso em fazer sua própria higiene bucal;

- Falta de informações sobre a maneira adequada de higienização das próteses.

A falta de informações sobre a higienização bucal foi relatada pelos CI como uma dificuldade no tocante à higienização oral dos idosos, fato que pode estar associado à deficiência ou ausência de repasse de informações por parte dos ACS e/ou do cirurgião-dentista.

Em seus estudos, Jitomirski (2000) faz referências ao programa "Protegendo a Vida" da Secretaria de Saúde do Estado do Paraná, no qual foi implementado um projeto de ação com base em um manual: "O que os cuidadores de idosos precisam saber sobre a saúde bucal". De acordo com os depoimentos dos participantes do projeto, algumas informações são obtidas, como, por exemplo, uso de próteses, condições de escovar os dentes sozinho, problemas de locomoção, dificuldades para comer, feridas ou úlceras de longa duração, boca seca, entre outras. 


\subsection{Categoria 3: o fazer educativo dos ACS}

Ao realizarem as visitas domiciliares, os ACS procuram orientar os idosos e principalmente seus cuidadores acerca da higiene oral e demais fatores ligados a problemas bucais decorrentes do processo de envelhecimento.

Conforme relatos dos ACS, uma expressiva parcela da população idosa acompanhada por eles é portadora de diabetes, sendo esses idosos insulinodependentes ou não - fato que se traduz em informações e orientações repassadas pelos ACS a estes, principalmente, aos seus cuidadores. Essas informações encontram-se detalhadas no Quadro 4.

Quadro 4 - Informações sobre cuidados e saúde bucal do idoso difundidas pelos Agentes Comunitários de Saúde (ACS) nas visitas domiciliares.

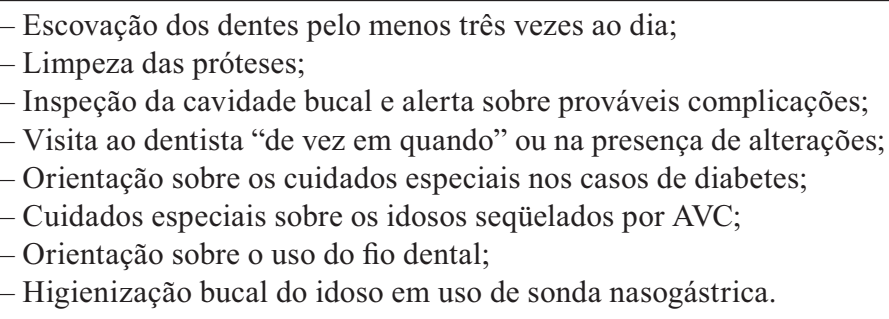

A higiene das próteses e dos dentes remanescentes, bem como o uso do fio dental na pessoa idosa, foram algumas das informações repassadas pelos ACS aos CI e idosos, durante as visitas domiciliares.

Segundo Pucca Junior (1996), as técnicas preconizadas para a remoção da placa bacteriana são várias. Ao se indicar uma técnica de higienização bucal para pessoas idosas, deve-se atentar para o grau de motricidade e o número de dentes ainda presentes na arcada. Levando-se em consideração a diminuição da capacidade motora na terceira idade, deve-se atentar para indicação de técnicas que sejam facilitadoras e individualizadas para propiciar a efetiva remoção dos detritos alimentares e da placa bacteriana. $\mathrm{O}$ mesmo autor também discorre sobre a higienização dos aparelhos protéticos, considerações as quais são importantes para a manutenção das próteses e a preservação de suas características fundamentais. 


\section{Considerações Finais}

Com a análise dos resultados, verificou-se que os objetivos propostos para o estudo foram alcançados, visto os depoimentos dos sujeitos da pesquisa sobre os conhecimentos acerca dos cuidados necessários à saúde bucal dos idosos atendidos pela ESF do município-alvo da pesquisa.

Entre os problemas e dificuldades que tiveram destaque nas falas dos sujeitos da pesquisa e que merecem uma atenção especial, podem-se citar o uso expressivo de próteses, em especial as dentaduras totais, a falta de higiene das mesmas, os acometimentos gengivais, a perda dos dentes naturais, os aparelhos protéticos mal adaptados causando lesões na cavidade oral, problemas sócio-econômicos para aquisição de próteses, a insistência do idoso em fazer sua própria higiene bucal e a falta de informações sobre a limpeza das dentaduras.

A ausência ou a insuficiente higiene tanto das próteses quanto da cavidade oral do idoso, fato relatado pelos ACS, pode ter relação com os problemas de ordem física e motora que acometem o indivíduo com o avançar da idade. Tais problemas ocorrem mesmo que o idoso insista em proceder com sua própria higiene oral.

Os ACS, peças fundamentais no processo preventivo-educativo da população, agem como elos entre equipe e usuários, de modo a colher e a difundir informações entre estes dois grupos. Neste sentido, os resultados mostram que este processo informativo-educativo está, de certa forma, acontecendo, ao passo que dados sobre escovação, uso de fio dental, limpeza das próteses, orientações e cuidados para idosos que se encontram em situações especiais (diabéticos e seqüelados de AVC) e alerta sobre problemas possivelmente encontrados durante inspeção bucal, estão sendo repassados pelos ACS durante as visitas domiciliares.

Porém, apesar de os ACS demonstrarem razoável conhecimento e tentarem repassar consideráveis informações aos cuidadores, parece haver uma dificuldade na compreensão destes dados pelos cuidadores, pois os mesmos dizem não saber informações de aspectos básicos principalmente sobre a higiene oral dos idosos, o que não confere com as falas dos ACS. Tal fato também pode estar ocorrendo por haver uma falha na comunicação entre profissional(is) e ACS no que se trata de informações específicas sobre prevenção, doenças e cuidados bucais para com os idosos.

Desta forma, pode-se concluir que um redimensionamento nas ações de assistência ao idoso deve ser realizado, essencialmente no que se refere 
ao programa de capacitação em saúde bucal na terceira idade, dirigido ao grupo de ACS e também aos CI.

Devido às dificuldades e problemas rotineiros e de grande desgaste físico e emocional para os cuidadores de idosos, uma forma de suporte a este grupo também pode ser de grande valia para o bom relacionamento entre população idosa, ACS e CI, bem como uma melhor qualidade de vida, principalmente dos CI. A retomada do grupo municipal de cuidadores, desativado há aproximadamente dois anos, vem a ser uma alternativa saudável e muito positiva.

\title{
KNOWLEDGE THAT HEALTH COMMUNITY AGENTS AND CARETAKERS OF SENIORS HAVE ABOUT ORAL HEALTH IN OLD AGE: experiences of the family health strategy in Victor Graeff
}

\begin{abstract}
The objective of the present study was to identify the knowledge that the ACS (health community agents) and the CI (caretakes of seniors) had, in Victor Graeff-RS Family Health Strategy's area, regarding the cares and oral health of senior people. There were eight ACS and four CI. The data collection was done through semi-driven interviews of group nature. The data were analyzed qualitatively through the use of analytical categories. The results allowed the identification of some aspects of the knowledge and the difficulties that ACS and CI have regarding the health and oral cares of the ederly, and also of the orientations that ACS give to CI during the home visiting.

Keywords: Gerontology. Oral health. Community agent of health. Senior. Caretakers of seniors. Family Health Strategy.
\end{abstract}

\section{REFERÊNCIAS}

BRASIL. Secretaria de Assistência à Saúde. Consolidado das famílias cadastradas no ano de 2006 da zona geral da equipe ESF. Victor Graeff: SIAB, 2006. Disponível em: Programa DAB DATASUS - versão 5.0. Acesso em: 10 mar. 2006.

CARVAlHO, Lígia Campos de; CORMACK, Elson Fontes. O Cuidado dos Idosos com suas Próteses Dentárias. Revista Brasileira de Odontologia, Rio de Janeiro, v. 60, n. 3, p. 167-169, maio/jun. 2003. 
CERQUEIRA, Ana Tereza de Abreu Ramos; OLIVEIRA, Nair Isabel Lapenta de. Programa de Apoio a Cuidadores: uma nova ação terapêutica e preventiva na atenção à saúde de idosos. Psicologia USP, São Paulo, v. 13, n. 1, p. 133-150, 2002. Disponível em: <http:// www.scielo.br/scielo.php?script $=$ sci_arttext\&pid=S0103-65642002000100007\&lng=iso $>$. Acesso em: 11 abr. 2006.

COSTA NETO, Milton Menezes (Org.). A Implantação da Unidade de Saúde da Família. Brasília, DF: Departamento de Atenção Básica, Secretaria de Políticas de Saúde, Ministério da Saúde, 2000.

FAJARDO, Renato Salviato; GRECCO, Patrícia. O que o Cirurgião-Dentista Precisa Saber para Compreender seu Paciente Geriátrico: parte 2: aspectos fisio-funcionais. $J B C$ : Jornal Brasileiro de Clinica Odontológica Integrada, Curitiba, v. 7, n. 41, p. 432-438, set./ out. 2003.

FERREIRA, Efigênia Ferreira; MAGALHÃES, Cláudia Silami de; MOREIRA, Allyson Nogueira. Promoção da Saúde Bucal para a População Idosa. In: CAMPOSTRINI, Eliana. Odontogeriatria. Rio de Janeiro: Revinter, 2004. P. 127-135.

HEBLING, Eduardo. Prevenção em Odontogeriatria. In: PEREIRA, Antonio Carlos. Odontologia em Saúde Coletiva: planejando ações e promovendo saúde. Porto Alegre: Artmed, 2003. P. 426-437.

JITOMIRSKI, Fanny. Atenção a idosos. In: PINTO, Vitor Gomes. Saúde Bucal Coletiva. 4. ed. São Paulo: Santos, 2000. P. 120-7.

KINA, Sidney; BELOTI, Adriana; BRUNETTI, Ruy Fonseca. Alterações da Sensibilidade Gustativa no Paciente Idoso. Atualidades em Geriatria, São Paulo, v. 3, n. 18, p. 20-23, ago. 1998. Disponível em: <http://www.drashirleydecampos.com.br/noticias/18606>. Acesso em: 12 fev. 2007.

MADEIRA, Ademar Américo; MADEIRA, Luciano. O paciente Geriátrico e a Complexidade de seu Atendimento. Revista Brasileira de Odontologia, Rio de Janeiro, v. 57, n. 6, p. 350-351, nov./dez. 2000.

MASTRANTONIO, Simone Di Salvo; GARCIA, Patrícia Petromilli Nordi Sasso. Programas Educativos em Saúde Bucal: revisão de literatura. JBP Jornal Brasileiro de Odontopediatria \& Odontologia do Bebê, Curitiba, v. 5, n. 25, p. 215-222, maio./jun., 2002.

MINAYO, Maria Cecília de Souza. O Desafio do Conhecimento: pesquisa qualitativa em saúde. 4. ed. São Paulo: Hucitec; Rio de Janeiro: Abrasco, 1995.

MYSSIOR, Ruth Necha. Aspectos Socias e Familiares no Envelhecimento. In: CAMPOSTRINI, Eliana. Odontogeriatria. Rio de Janeiro: Revinter, 2004. P. 28-31.

PARAJARA, Fabiana; GUZZO, Fernanda. Sim, é Possível Envelhecer Saudável! Revista Regional de Araçatuba, São Paulo, v. 54, n. 2, p. 91-99, mar./abr. 2000. 
PAVARINI, Sofia Cristina Iost et al. De Necessidades à Intervenção: etapas na organização de um serviço de orientação para cuidadores de idosos. In: SEMINÁRIO DE METODOLOGIA PARA PROJETOS DE EXTENSÃO, 4., 2001, São Carlos. 2001. Anais Eletrônicos . . Rio de Janeiro: UFRJ, 2001. Disponível em: <http://www.itoi.ufrj.br/ sempe/t1-p27.htm>. Acesso em: 04 abr. 2006.

PUCCA JUNIOR, Gilberto Alfredo. A Saúde Bucal do Idoso: aspectos sociais e preventivos. In: NETTO, Matheus Papaleo. Gerontologia. São Paulo: Atheneu, 1996. P. 297-309.

RODRIGUES, Suely Maria; VARGAS, Andréa Maria Duarte; MOREIRA, Alyson Nogueira. Percepção de saúde bucal em idosos. Arquivos em Odontologia, Belo Horizonte, v. 39, n. 3, p. 163-254, jul./set. 2003.

Recebido em: 17-03-2008

$1^{a}$ revisão: 05-05-2008

$2^{a}$ revisão: $23-11-2008$

Aceite final: 18-12-2008 